\title{
Event-related brain potentials reflect traces of echoic memory in humans
}

\author{
ISTVAN WINKLER \\ Institute for Psychology, Hungarian Academy of Sciences, Budapest, Hungary \\ and \\ KALEVI REINIKAINEN and RISTO NÄÄTÄNEN \\ University of Helsinki, Helsinki, Finland
}

\begin{abstract}
In sequences of identical auditory stimuli, infrequent deviant stimuli elicit an event-related brain potential component called mismatch negativity (MMN). MMN is presumed to reflect the existence of a memory trace of the frequent stimulus at the moment of presentation of the infrequent stimulus. This hypothesis was tested by applying the recognition-masking paradigm of cognitive psychology. In this paradigm, a masking sound presented shortly before or after a test stimulus diminishes the recognition memory of this stimulus, the more so the shorter the interval between the test and masking stimuli. This interval was varied in the present study. It was found that the MMN amplitude strongly correlated with the subject's ability to discriminate between frequent and infrequent stimuli. This result strongly suggests that MMN provides a measure for a trace of sensory memory, and further, that with MMN, this memory can be studied without performance-related distortions.
\end{abstract}

Auditory stimuli presented in temporal proximity interfere with each other in perception. The influence of one sound on the recognition of the other is studied in the recognition-masking paradigm. In it, subjects are required to identify sounds (test sound) preceded or followed by another sound (masking sound) with a short silent interval (intertone interval). In forward masking, the masking stimulus precedes the test stimulus; in backward masking, this order is reversed. The masking paradigms have been widely used to assess features of the auditory sensory store (echoic memory; for a review, see Hawkins \& Presson, 1986; see also Cowan, 1984, 1988). Increasing the intertone interval between the two sounds until recognition performance reaches an asymptotic level establishes the time required for the emergence of a relatively stable trace in echoic memory (for a review, see Massaro, 1976). However, the subject's discrimination task in these experiments might distort results by introducing performancerelated processes.

The mismatch negativity (MMN) is a component of the event-related brain potential (ERP) elicited by infrequent, physically deviant stimuli (e.g., a pitch or intensity change) in a sequence of auditory stimuli (standards). (For a review, see Näätänen, 1990.) MMN is elicited even in passive paradigms-that is, when the subject's task is not related to the auditory stimuli (see, e.g., Alho, Sams, Paavilainen, Reinikainen, \& Näätänen, 1989; Alho,

This research was supported by the Academy of Finland and the National Scientific Fund of Hungary (OTKA). Correspondence should be addressed to I. Winkler, Institute for Psychology, Hungarian Academy of Sciences, H-1394 Budapest, P.O.B. 398, Szondy u. 83-85, Hungary.
Woods, Algazi, \& Näätänen, 1992). In order to elicit the MMN component, the deviant stimulus has to be preceded by several exemplars of the standard stimulus (Sams, Alho, \& Nääıänen, 1983); infrequent stimuli alone do not elicit the MMN (Näätänen, Paavilainen, Alho, Reinikainen, \& Sams, 1989). The intracranial generators of the MMN are bilaterally localized in the primary auditory cortex or in its vicinity (Hari et al., 1984), and possibly in the right frontal lobe (Giard, Perrin, Pernier, \& Bouchet, 1990).

These findings suggest that MMN reflects a neural process activated when an incoming stimulus does not correspond to the trace formed by the previous stimuli. Memory traces involved in change detection might form the neurophysiological basis of echoic memory (Näätänen, 1985). The MMN amplitude probably enables one to assess the strength of this trace. This relationship is supported by the effects of the interstimulus interval (see, e.g., Mäntysalo \& Näätänen, 1987), the deviant-stimulus probability (see, e.g., Näätänen, Sams, Järvilehto, \& Soininen, 1983), and variation of the standard stimulus on MMN (Winkler et al., 1990). Increasing the interstimulus interval in the sequence, decreasing the withinblock probability of the standard stimulus (thus increasing that of the deviant stimulus), or introducing some variation in the standard stimulus decreases the strength of the standard-stimulus trace encountered by deviants. Each of these manipulations also attenuates the MMN amplitude.

The alternative to this memory-trace hypothesis is that MMN is due to release from refractoriness. According to the refractoriness hypothesis, the extra negativity in ERPs to infrequent stimuli is generated by such neural elements that respond to the specific feature(s) separating infrequent from frequent stimuli. These neurons would 


\section{Forward Masking}

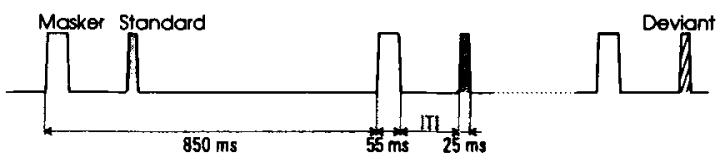

\section{Backward Masking}

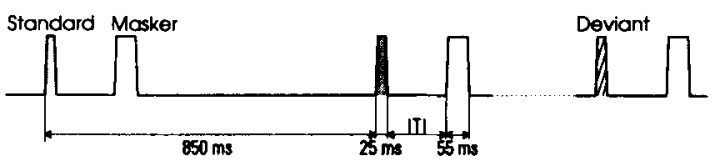

Figure 1. Order of stimuli within the stimulus pairs and timing information in forward and backward masking. Standards are marked with dotted fill; deviants, with hatched pattern; masking stimuli are left empty. ITI, intertone interval.

not be exhausted by the frequent repetition of the standard stimulus; therefore, they would account for all the extra negativity elicited by deviants in relation to that elicited by the standards (Näätänen, 1990).

The present study addressed MMN in the auditory recognition-masking paradigm. Good correspondence between recognition memory and MMN would (1) strongly support the memory interpretation of MMN, (2) provide a measure for echoic memory uncontaminated by the subject's task, and (3) give an estimate for the buildup time of the memory trace involved.

\section{METHOD}

Both forward-and backward-masking experiments were carried out in two sessions each. In the MMN session, the subject was required to read a book and to ignore auditory stimuli while the EEG was recorded. In the recognition masking session, held on a separate day (no EEG was recorded), the same stimuli were administered and the subject was instructed to press a button in response to the higher (infrequent) test tones.

Ten subjects (18-32 years, 8 males) participated in the backwardmasking experiment. Five of them (19-30 years, all males), selected on the basis of showing no ceiling effect in backward recognition masking (sce Results), participated later in the forward-masking study, too. These five subjects were then subsequently retested in a session of backward recognition masking to check whether their previous experience with the stimuli affected their performance in forward masking.

The subject sat in a reclining chair in an electrically and acoustically shielded room. Pairs of sine-wave tone bursts (intensity, $80 \mathrm{~dB}$ SPL) were presented via earphones to the subject's right ear. The interval between onsets of consecutive pairs of test and masker tones was constant at $850 \mathrm{msec}$, the durations being 25 and $55 \mathrm{msec}$, respectively (including $2.5-\mathrm{msec}$ linear rise and fall times). Figure 1 illustrates the stimulus sequences of both masking conditions. Of the test tones, $85 \%$ had a frequency of $600 \mathrm{~Hz}$ (standard test tone), and $15 \%$, a frequency of $700 \mathrm{~Hz}$ (deviant test tone). The masker tone had a frequency of $1000 \mathrm{~Hz}$. The order of pairs containing the frequent or the infrequent test tone was randomized. Stimulus pairs of different intertone intervals were presented in separate blocks (250 pairs/block, five blocks for each intertone interval in the MMN session, two blocks in the recognition-masking session). The order of the blocks was balanced with respect to the intertone intervals. The intertone intervals were $20,50,150,300$, and $400 \mathrm{msec}$.

The EEG was recorded with $\mathrm{Ag}-\mathrm{AgCl}$ electrodes at $\mathrm{Fpz}, \mathrm{Fz}, \mathrm{Cz}$, Pz, F3, C3, F4, C4 (10-20 system), and both mastoids. The reference electrode was placed on the tip of the nose. The horizontal EOG was monitored with an electrode attached to the outer canthus of the right eye for artifact rejection. The EEG was amplified (bandpass limits: 0.1-100 Hz) and digitized (sampling rate, $200 \mathrm{~Hz}$ ). The analysis period was $420 \mathrm{msec}$ (including 15 -msec prestimulus time). Trials with an EEG- or EOG-amplitude change exceeding $150 \mu \mathrm{V}$ were rejected. Digitized epochs were averaged within each intertone interval/stimulus class and filtered below $30 \mathrm{~Hz}$. The MMN amplitude was measured from the difference between ERPs to infrequent (deviant) and frequent (standard) test stimuli in the $160-200 \mathrm{msec}$ interval (MMN interval); the $\mathrm{N} 1$ amplitude, from the $80-120$ msec interval (N1 interval) of the standard-stimulus responses. Results from the electrode position (Fz), yielding the most prominent MMN, were used for statistical testing. This choice was encouraged by high correlations between $\mathrm{MMN}$ amplitudes at neighboring electrode locations (over .84 in forward, over .77 in back ward masking).

The recognition-masking session was preceded by a short initial training period. (Blocks presented for training contained the same test tones used throughout the experiment but without masking.) Recognition performance was calculated as the ratio of the correct buttonpresses in response to the total number of the infrequent test tones. Low false-alarm rates (below $3 \%$ for each subject/condition) made the calculation of $d^{\prime}$ values unnecessary.

The presence of the MMN component was tested by one-factor analyses of variance between the average amplitudes in the MMN interval of ERPs to deviants and the corresponding standards. The effect of the intertone interval was tested by one-factor analyses of variance with repeated measures (Huynh-Feldt correction applied) of the MMN amplitude and of the recognition performance, followed by Scheffé-type pairwise comparisons. The relation between the MMN amplitude and recognition performance was tested by polynomial regression between recognition performance and the MMN amplitude. Statistical tests were computed with the BMDP software package (Dixon, 1985).

\section{RESULTS}

In backward recognition masking, 5 out of 10 subjects correctly identified more than $90 \%$ of the deviant test tones even at the shortest intertone interval $(20 \mathrm{msec})$. (Table 1 shows the recognition performance and the MMN amplitudes measured for this group.) Because of this recognition performance ceiling effect, only data collected from the other 5 subjects (no-ceiling-effect group) were included in the subsequent analyses. Figure 2 shows for these subjects that, only when followed by longer in-

Table 1

Recognition Performance (Percent) and Average Frontal Mismatch Negativity (MMN) Amplitude (in Microvolts) for the Different Intertone Intervals (in Milliseconds) in Backward Masking

\begin{tabular}{lccccc}
\hline & \multicolumn{5}{c}{ Intertone Interval } \\
\cline { 2 - 6 } & 20 & 50 & 150 & 300 & 400 \\
\hline MMN & -0.57 & -0.70 & -0.88 & -0.61 & -0.90 \\
\%Hits & 97.37 & 95.79 & 88.42 & 95.79 & 96.32 \\
\hline
\end{tabular}

Note-Data were measured from subjects detecting more than $90 \%$ of deviants at the 20 -msec intertone interval (ceiling-effect group). 
Backward Masking

$\mathrm{Fz}$

'No-cejling-effect' group

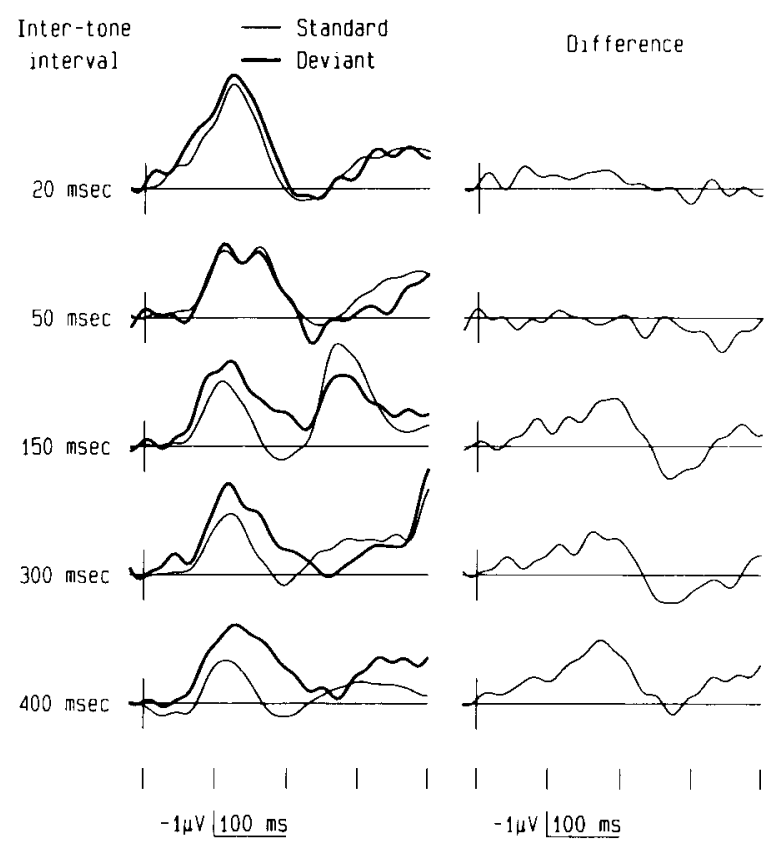

Figure 2. Left: Across-subject averaged (no-ceiling-effect group) frontal (Fz) ERPs to the frequent (thin line) and infrequent (thick line) test tones in the backward-masking condition. Right: Difference curves obtained by subtracting ERPs to frequent test stimuli from those to infrequent test stimuli. Different rows represent different intervals between the test-stimulus offset and the maskerstimulus onset (intertone interval): 20, 50, 150, 300, and 400 msec. tertone intervals ( $>150 \mathrm{msec}$ ) did deviants elicit a significantly larger negativity in the $\mathrm{MMN}$ interval than did the corresponding standards $[F(1,4)=2.45 ; F(1,4)=$ $0.19 ; F(1,4)=5.08, p<.0872 ; F(1,4)=9.54, p<$ $.0366 ; F(1,4)=16.48, p<.0153$; for the 20-, 50-, 150-, $300-$, and $400-\mathrm{msec}$ intertone intervals, respectively]. The scalp distribution of the difference between ERPs to deviants and to standards in the MMN interval (see Figure 3 for the 400 -msec intertone interval blocks) displays the characteristic features of the MMN component (frontocentral dominance, polarity inversion toward the mastoids), being significantly different from those of the N1 component. ' Thus, MMN was elicited at longer intertone intervals, its amplitude being significantly larger at long than at short intertone intervals $[F(4,16)=8.31, p<$ $.0015] .{ }^{2}$ The intertone interval dependence of the MMN amplitude in backward masking was replicated in 10 subjects for both ipsi- and contralateral masking in a recent study of Winkler and Näätänen (1992), who used the same paradigm and stimuli. Recognition performance was at about chance level with short intertone intervals (25.3\% at the $20-\mathrm{msec}$, and $12.6 \%$ at the 50 -msec intertone interval; the latter percentage means 4-5 detected deviants out of the 38 presented in a block, with about the same amount of false alarms) but reached a high level with the longer intervals $[F(4,16)=9.3, p<.0005] .{ }^{3}$ The relationship between the $\mathrm{MMN}$ amplitude and recognition performance as functions of the intertone interval was linear (see Figure 6, right side; Table 2). In a polynomial regression between the mean-corrected subject-by-subject MMNamplitude and recognition-performance measurements, the goodness-of-fit test was not significant for degrees greater than zero [e.g., $F(3,20)=1.04, F(2,20)=0.37$, etc. . $^{4}$

Backward Masking
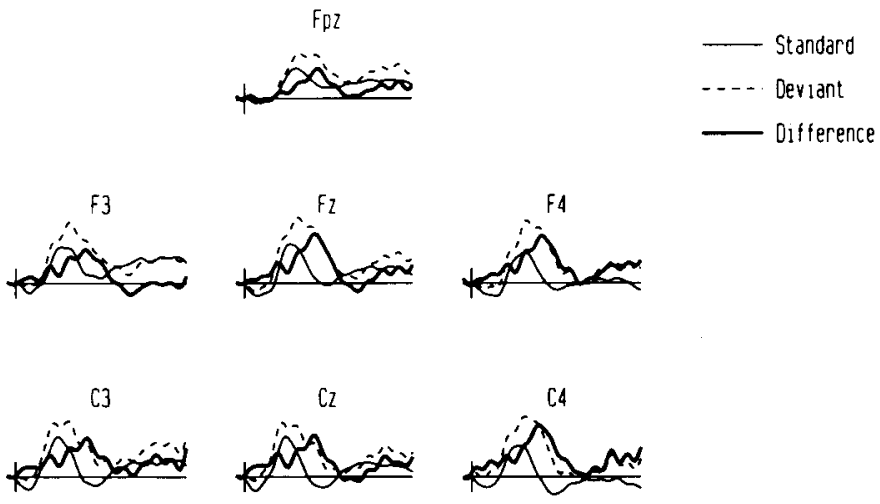

ML

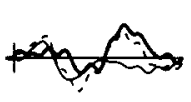

$P_{2}$

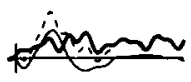

$$
-2 \mu v 100 m
$$

NQ

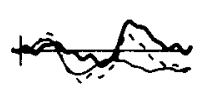

Figure 3. Across-subject averaged (all subjects) ERPs to frequent (thin continuous line) and infrequent (dashed line) test tones, and the corresponding difference curves (thick continuous line) in backward masking at the $\mathbf{4 0 0}$-msec intertone interval. 
Table 2

Recognition Performance (Percent) and Average Frontal Mismatch Negativity (MMN) Amplitude (in Microvolts) for the Different Intertone Intervals (in Milliseconds) in Backward Masking

\begin{tabular}{lrrrrr}
\hline & \multicolumn{5}{c}{ Intertone Interval } \\
\cline { 2 - 6 } & 20 & 50 & 150 & 300 & 400 \\
\hline MMN & -0.63 & +0.16 & -1.76 & -1.50 & -2.28 \\
\%Hits & 25.26 & 12.63 & 63.16 & 74.74 & 85.72 \\
\hline
\end{tabular}

Note-Data were measured from subjects detecting less than $90 \%$ of deviants at the 20-msec intertone interval (no-ceiling-effect group).

In forward masking (only subjects from the no-ceilingeffect group participated in the experiment), deviants elicited a significantly larger negativity in the MMN interval than did standards (Figure 4) at each intertone interval $[F(1,4)=28.78, p<.0058 ; F(1,4)=16.85, p<$ $.0148 ; F(1,4)=81.31, p<.0008 ; F(1,4)=37.69, p<$ $.0036 ; F(1,4)=11.17, p<.0288$; for $20-, 50-, 150-$, 300 -, and 400-msec intertone intervals, respectively]. The scalp distribution of the difference between ERPs to deviants and the corresponding standards in the MMN interval was similar to that in backward masking (Figure 5), and significantly different from that of the N1 component. The MMN amplitude to deviants was low at the shortest intertone interval $(20 \mathrm{msec})$; it increased with increasing intervals until the $300-\mathrm{msec}$ interval; and it was again lower at the 400-msec interval $[F(4,16)=3.83, p<$ $.0356] .{ }^{6}$ Recognition performance varied with the intertone interval in a similar manner $[F(4,16)=9.81, p<$ $.0006] .^{7}$ The relationship between the MMN amplitude and recognition performance as functions of the intertone interval was again linear (see Figure 6, left side; cf. Table 3). In a polynomial regression between the mean-corrected subject-by-subject $\mathrm{MMN}$-amplitude and recognitionperformance measures, the goodness-of-fit test was not significant for degrees greater than zero [e.g., $F(3,20)=$ $0.60, F(2,20)=0.36$, etc. $]$.

With short intertone intervals ( 20 and $50 \mathrm{msec}$ ), backward masking was more effective than forward masking. Both recognition performance and the average difference in the MMN interval were significantly lower in backward than in forward masking (in two-factor analyses of variance of forward vs. backward masking $x$ intertone interval ( 20 vs. $50 \mathrm{msec}$ ), the condition factor being significant for both $\mathrm{MMN}$ amplitude and recognition performance $[F(1,4)=8.30, p<.0450$, and $F(1,4)=$ $27.89, p<.0062$, respectively]. The highest MMN amplitude of the two masking conditions was recorded from 300 -msec intertone interval blocks in forward masking. A one-factor analysis of variance (intertone interval) using measurements from the 300 - and 400 -msec intertone interval blocks of each condition revealed a significant $\mathrm{MMN}$-amplitude difference $[F(3,12)=4.28, p<.0285]$. Although recognition performance reached its maximum together with the MMN amplitude, a similar analysis of the percent of correct responses failed to reach significance. Neither forward nor backward masking had a significant effect on the latency of the MMN component.
Table 4 shows results from the retest of backward recognition masking. In a two-factor analysis of variance (original vs. retest session $\times$ intertone interval), no significant difference was found between the two sessions $[F(1,4)=0.06]$, whereas the effect of the intertone interval was again highly significant $[F(4,16)=16.23, p<$ $.0017]$. These results suggest that the subjects' previous experience with the stimuli did not affect their performance significantly in the forward-masking condition.

\section{DISCUSSION}

The memory-trace hypothesis of mismatch negativity claims that the component reflects a neural process activated by some physical difference between the present stimulus and the trace of the repeated standard stimulus. The trace assumed to underlie MMN contains extracted auditory information of fine resolution and is available for comparison for a few seconds after the last repetition of the standard stimulus. Although even one occurrence of a stimulus should result in the formation of a memory trace, stimulus repetition might be necessary to set the context (the standard status of the stimulus) for the mismatch process, for MMN is elicited even in the absence of focused attention.

\section{Forward Masking \\ Fz}

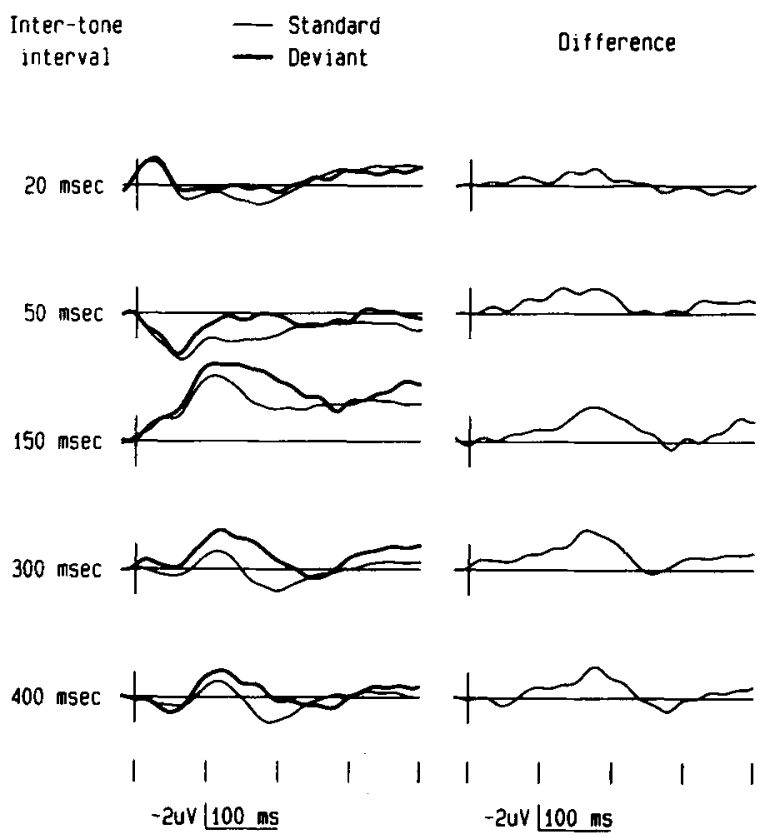

Figure 4. Left: Across-subject averaged frontal (Fz) ERPs to the frequent (thin line) and infrequent (thick line) test tones in the forward-masking condition. Right: Difference curves obtained by subtracting ERPs to frequent test stimuli from those to infrequent test stimuli. Different rows represent different intervals between the masker-stimulus offset and the test-stimulus onset (intertone interval): $20,50,150,300$, and 400 msec. 
Forward Masking
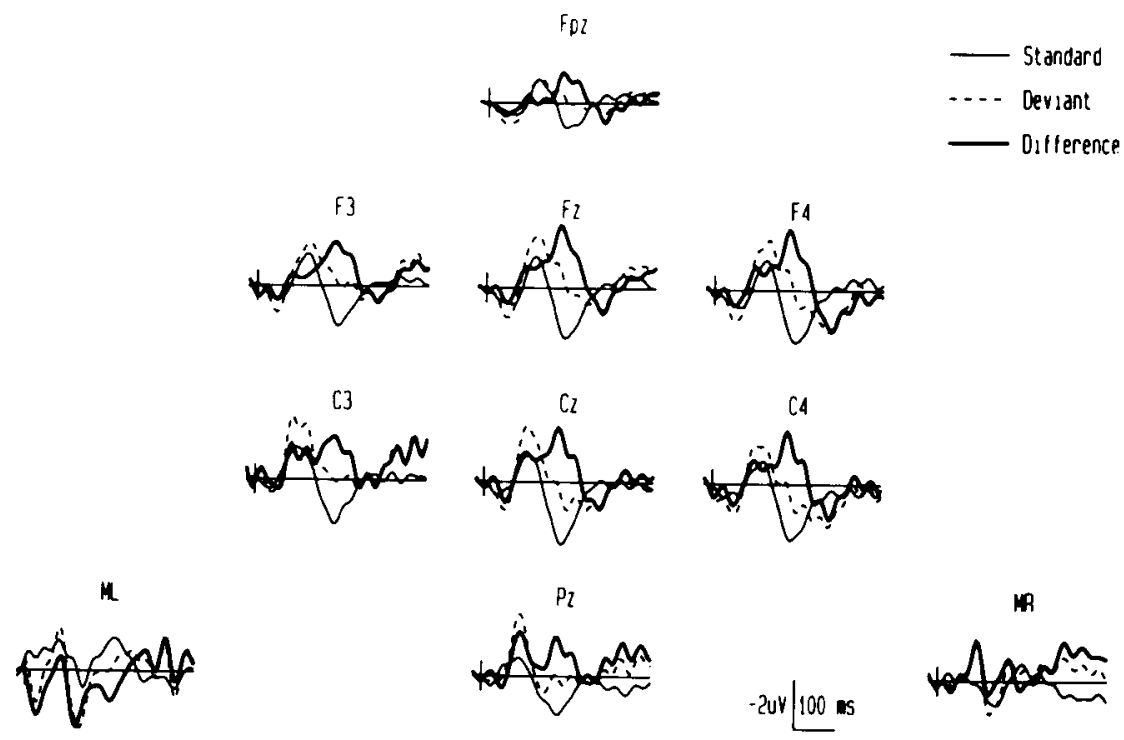

Figure 5. Across-subject averaged ERPs to frequent (thin continuous line) and infrequent (dashed line) test tones and the corresponding difference curves (thick continuous line) in forward masking at the $400-m s e c$ intertone interval.

\section{Forward and Backward Masking MMN amplitude and recognition performance}

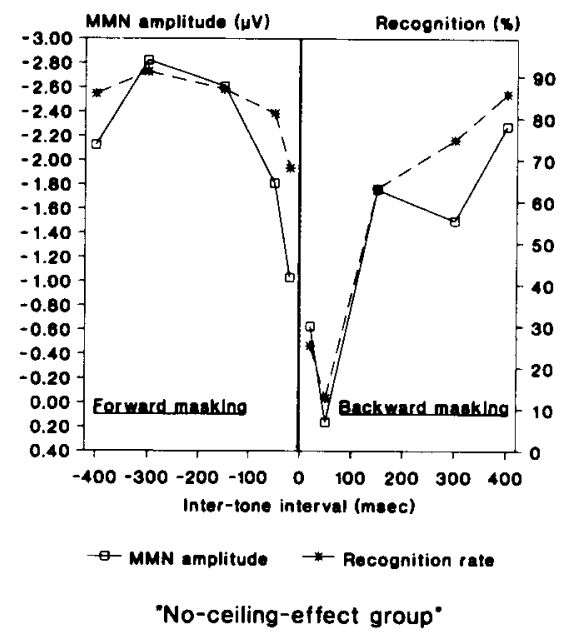

Figure 6. Left: Forward masking. Across-subject averaged frontal (Fz) mismatch negativity (MMN) amplitude in microvolts (mean of the 160- to 200-msec interval; continuous line; left scale) and the percentage of correctly detected infrequent stimuli (dashed line; right scale) as a function of the intertone interval. Right: Backward masking. Across-subject averaged (no-ceiling-effect group) frontal (Fz) mismatch negativity (MMN) amplitude in microvolts (mean of the 160- to 200-msec interval; continuous line; left scale) and the percentage of correctly detected infrequent stimuli (dashed line; right scale) as a function of the intertone interval.
The very good correspondence between the MMN amplitude and recognition performance as a function of the intertone interval found in both masking conditions strongly supports this memory-trace interpretation of MMN. ${ }^{8}$ This is in particular supported by the elimination of recognition memory and MMN with short intertone intervals in the backward-masking condition. ${ }^{9}$ Moreover, the MMN amplitude was more strongly attenuated in backward than in forward masking (see Figure 6; cf. Tables 2 and 3), which is consistent with behavioral findings according to which backward masking eliminates recognition memory more effectively than does forward masking (e.g., Massaro, Cohen, \& Idson, 1976). Furthermore, in accordance with behavioral findings of recognition performance, the masking tone in backward masking still attenuates the MMN amplitude with longer intertone intervals than does the masking tone in forward masking. This was shown in the analysis of the pooled data from the 300- and 400-msec intervals of both conditions: the MMN amplitude increased significantly from the 300-msec interval in backward masking to the 300 msec interval in forward masking (this would be a 470 msec intertone interval in terms of backward masking). ${ }^{10}$ With both of these intertone intervals, the masker tone was presented more than $200 \mathrm{msec}$ after the onset of the test tone (i.e., the end of the MMN measurement interval). Because in this case the masker was presented after the MMN offset, it could not affect the MMN amplitude via the mismatch process itself. Therefore, in accordance 
Table 3

Recognition Performance (Percent) and Average Frontal MMN Amplitude (in Microvolts) for the Different Intertone Intervals (in Milliseconds) in Forward Masking

\begin{tabular}{lrrrrr} 
& \multicolumn{5}{c}{ Intertone Interval } \\
\cline { 2 - 6 } & 20 & 50 & 150 & 300 & 400 \\
\hline MMN & -1.03 & -1.81 & -2.61 & -2.82 & -2.12 \\
\%Hits & 68.02 & 81.05 & 86.84 & 91.05 & 85.79 \\
\hline
\end{tabular}

Table 4

Recognition Performance (Percent) for the Different Intertone Intervals (in Milliseconds) Measured in the Retest Session of Backward Masking

\begin{tabular}{cccccc} 
& \multicolumn{5}{c}{ Intertone Interval } \\
\cline { 2 - 6 } & 20 & 50 & 150 & 300 & 400 \\
\hline \% Hits & 16.32 & 37.90 & 61.58 & 73.16 & 81.05 \\
\hline
\end{tabular}

with the memory-trace hypothesis of MMN, the significant increase of the MMN amplitude must reflect the weaker masking (and thus stronger trace) of the standard stimulus. This finding suggests that backward masking affects the memory trace (depending on the length of the intertone interval) even in the absence of focused attention. It is hard to reconcile this result with the purely attentional interpretation of backward recognition masking (Hawkins \& Presson, 1986).

Results from this study show that although approximately $150 \mathrm{msec}$ are sufficient for the extraction of pitch information (in order to elicit the MMN component), further enhancement of the echoic trace might last as long as $470 \mathrm{msec}$ (because, in terms of backward masking, the MMN amplitude increases to a $470-\mathrm{msec}$ intertone interval; see Note 9). This is consistent with both stimulus(Foyle \& Watson, 1984) and performance-based (for a review, see Cowan, 1984) estimates of the trace-formation time.

Although masking affects the detectability of the deviant stimulus, no change in the latency of the MMN component could be observed. Such a latency shift could have been expected, since the latency of the MMN component changes with the physical difference between standard and deviant stimuli (the larger the separation, the shorter the MMN latency; Näätänen \& Gaillard, 1983; Winkler, Paavilainen, \& Näätänen, 1992). The lack of the latency effect suggests that MMN latency is affected by physical separation, but not by discriminability in general (even though the amount of deviation is a factor of discriminability).

The present MMN results from backward masking are in agreement with two-trace models of auditory sensory memory, suggesting that the immediate effect of a sound is the development of a trace that decays rapidly and can be overwritten by the next sound if it occurs in close succession (for a review, see Cowan, 1984). In the absence of the next sound, this initial trace is converted into a more stable form of storage that consecutive stimuli can only partially interfere with. Features of the memory store deduced from MMN studies are compatible with the corresponding features of the longer lasting form of the auditory stimulus representation (inferred from behavioral results, see Cowan, 1984). The duration of an MMN trace, as estimated from the effects of stimulus rate on MMN (see, e.g., Mäntysalo \& Näätänen, 1987), is several seconds. The store can hold at least two traces in parallel (inferred from sequential effects on MMN; see Sams, Alho, \& Näätänen, 1984, and Winkler et al., 1992). The estimated time of trace formation is between 150 and $470 \mathrm{msec}$ (on the basis of the present results). This correspondence anchors MMN studies to the context of psychological models of auditory sensory memory. In the future, the MMN paradigm might prove to be an important tool for investigating and possibly also for localizing this memory (Näätänen, 1992).

\section{REFERENCES}

Alho, K., Sams, M., Paavilainen, P., Reinikainen, K., \& NÄÄTÄNEN, R. (1989). Event-related brain potentials reflecting processing of relevant and irrelevant stimuli during selective listening. Psychophysiology, 26, 514-528.

Alho, K., Woods, D. L., Algazi, A., Nä́tänen, R. (1992). Intermodal selective attention: II. Effects of attentional load on processing of auditory and visual stimuli in central space. Electroencephalography \& Clinical Neurophysiology, 82, 356-368.

Cowan, N. (1984). On short and long auditory stores. Psychological Bulletin, 96, 341-370.

Cowan, N. (1988). Evolving conceptions of memory storage, selective attention, and their mutual constraints within the human information-processing system. Psychological Bulletin, 104, 163-191.

DixoN, W. J. (1985). BMDP Statistical Software manual. Berkeley: University of California Press.

Foyle, D. C., \& Watson, C. S. (1984). Stimulus-based versus performance-based measurement of auditory backward recognition masking. Perception \& Psychophysics, 36, 515-522.

Giard, M.-H., Perrin, F., Pernier, J., \& Bouchet, P. (1990). Brain generators implicated in processing of auditory stimulus deviance: A topographic event-related potential study. Psychophysiology, 27, 627-640.

Hari, R., hämäläinen, M., Ilmoniemi, R., Kaukoranta, E., Reinikainen, K., Salminen, J., Alho, K., NäÄtänen, R., \& Sams, M. (1984). Responses of the primary auditory cortex to pitch changes in a sequence of tone pips: Neuromagnetic recordings in man. Neuroscience Letters, 50, 127-132.

Hawkins, H. L., \& Presson, J. C. (1986). Auditory information processing. In K. R. Boff, L. Kaufman, \& J. P. Thomas (Eds.), Handbook of perception and human performance (pp. 26.1-26.64). New York: Wiley.

MäntYSALO, S., \& NÄÄTÄNEN, R. (1987). The duration of a neuronal trace of an auditory stimulus as indicated by event-related potentials. Biological Psychology, 24, 183-195.

Massaro, D. W. (1976). Auditory information processing. In W. K. Estes (Ed.), Handbook of learning and memory (pp. 275-320). Hillsdale, NJ: Erlbaum.

Massaro, D. W., Cohen, M. M., \& IDson, W. L. (1976). Recognition masking of auditory lateralization and pitch judgments. Journal of the Acoustical Society of America, 59, 434-441.

NÄÄTÄNEN, R. (1985). Selective attention and stimulus processing: Reflections in event-related potentials, magnetoencephalogram, and regional cerebral blood flow. In M. I. Posner \& O. S. M. Marin (Eds.), Attention and performance XI (pp. 355-373). Hillsdale, NJ: Erlbaum. 
NÄÄTÄNEN, R. (1990). The role of attention in auditory information processing as revealed by event-related potentials and other brain measures of cognitive function. Behavioral \& Brain Sciences, 13, 201-288.

NÄÄTÄNEN, R. (1992). Attention and brain function. Hillsdale, NJ: Erlbaum.

NäÄtÄnen, R., Gaillard, A. W. K. (1983). The orienting reflex and the N2 deflection of the ERP. In A. W. K. Gaillard \& W. Ritter (Eds.), Tutorials in event-related potential research: Endogenous components (pp. 119-141). Amsterdam: Elsevier.

Nä̈tänen, R., Paavilainen, P., Alho, K., Reinikainen, K., \& SAMS, M. (1989). Do event-related potentials reveal the mechanism of the auditory sensory memory in the human brain? Neuroscience Letters, 98, 217-221.

NÄ̈̈tänen, R., SAms, M., Järvilehto, T., Soininen, K. (1983) Probability of deviant stimulus and event-related brain potentials. In R. Sinz \& M. R. Rosenzweig (Eds.), Psychophysiology 1980 (pp. 397-405). Jena: VEB Gustav Fischer Verlag; Amsterdam: Elsevier Biomedical.

Sams, M., Alho, K., \& Nä̈tÄnen, R. (1983). Sequential effects in the ERP in discriminating two stimuli. Biological Psychology, 17, 41-58.

Sams, M., Alho, K., \& NäÄtänen, R. (1984). Short-term habituation and dishabituation of the mismatch negativity of the ERP. $P_{s y-}$ chophysiology, 21, 434-441.

WINKLER, I., NÄ̈̈T̈̈NEN, R. (1992). Event-related potentials in auditory backward recognition masking: A new way to study the neurophysiological basis of sensory memory in humans. Neuroscience Letters, 140, 239-242.

Winkler, I., Paavilainen, P., Alho, K., Reinikainen, K., SAMS, M., \& NÄ̈̈TÄNEN, R. (1990). The effect of small variation of the frequent auditory stimulus on the event-related brain potential to the infrequent stimulus. Psychophysiology, 27, 228-235.

Winkler, I, PaAvilainen, P. NäÄtänen, R. (1992). Can echoic memory store two traces simultaneously? A study of event-related brain potentials. Psychophysiology, 29, 337-349.

\section{NOTES}

1. In backward masking, the $\mathrm{MMN}$ scalp distribution was significantly more frontal than that of $\mathrm{Nl}$ at the largest intertone interval $(400 \mathrm{msec})$. In a two-factor analysis of variance (MMN vs. $\mathrm{Nl} \times \mathrm{Fz}$ vs. $\mathrm{Cz}$ ) the interaction between the factors was significant $[F(1,9)=6.80, p<$ .0284 ], whereas none of the main effects were. Because $M M N$ was present in the responses of all subjects, both subject groups (ceiling effect and no ceiling effect) were included in this analysis.

2. Scheffe-type pairwise comparisons showed that the difference between ERPs to deviants and to standards in the MMN interval was significantly larger for the blocks with 150-, 300-, and 400-msec intertone intervals than for the blocks with 50 -msec intertone intervals $[F(3,12)=$ $4.62, p<.05 ; F(3,12)=4.47, p<.05$; and $F(3,12)=7.39, p<$ .01 , respectively] and for the blocks with 400 -msec intertone intervals than for those with 20 -msec intervals $[F(3,12)=3.61, p<.05]$.

3. The recognition rate of deviants followed by $150-, 300-$, and $400-$ msec intertone intervals was higher than that of deviants followed by intervals of 20 or 50 msec [e.g., Scheffe-type pairwise comparisons for the percentage of correct responses between 50- and 150-msec blocks and between $20-$ and $400-$ msec blocks: $F(3,12)=3.74, p<.05$, and $F(3,12)=11.70, p<.01$, respectively $]$.

4. A comparison of Tables 1 and 2 shows that considerably larger MMN amplitudes were measured for subjects in the no-ceiling-effect group, together with performance levels lower than those in the ceilingeffect group. This is due to the large interindividual variability of the MMN amplitude (see, e.g., Winkler \& Näätänen. 1992, Figure 3) caused by (at least partially) anatomical differences controlling the location and direction of the MMN generators in the auditory conex. Because of this fact, the relationship between $\mathrm{MMN}$ amplitude and performance in recognition masking can only be studied within subjects (as is done in this study) and not between small groups of subjects. Note also that the MMN amplitude level is stable within subjects (e.g., compare the MMN amplitudes of Tables 2 and 3).

5. The scalp distribution of the present MMN component was significantly anterior to that of $\mathrm{NI}$ at the largest intertone interval $(400 \mathrm{msec})$ of forward masking. In a two-factor analysis of variance (MMN vs. $\mathrm{N} 1 \times \mathrm{Fz}$ vs. $\mathrm{Cz}$ ) the interaction between the factors was significant $[F(1,4)=27.85, p<.0062]$, whereas none of the main effects were.

6. Scheffe-type pairwise comparisons showed that deviants following a 150- or 300 -msec intertone interval elicited a larger MMN than did those following a 20 -msec interval $[F(3,12)=4.54, p<.05$, and $F(3,12)=5.86, p<.05$, respectively 1 .

7. The recognition rate of deviants for the 20 -msec intertone interval was lower than that for any other interval, and the recognition rate for the 50-msec interval was lower than that for the $300-\mathrm{msec}$ interval [Scheffé-type pairwise comparisons for the percentage of correct responses between, e.g., 20- and 50-msec blocks and between 50- and 300-msec blocks: $F(3,12)=5.79, p<.05$, and $F(3,12)=3.63, p<$ .05 , respectively].

8. The similar effect of the intertone interval on the MMN amplitude and recognition performance could also be explained by assuming that MMN reflects the process of sensory-information extraction (and not the resulting memory trace). However, other features of the MMN component rule out this possibility. Näatanen et al. (1983) found that the MMN amplitude decreases with increasing deviant-stimulus probabilities (all other parameters held constant; only the ratio of standard vs. deviant stimulus presentation was varied). While there is no reason to assume that the sensory feature analysis of the standard becomes less complete with increasing deviant probabilities, the attenuation of the MMN amplitude can be explained by weaker memory traces (due to less frequent repetition of the standard).

9. Although the intertone interval might affect the refractory effect of the masker tone on the test stimuli in general, there is no reason to believe that this effect should be stronger for standards than for deviants. Therefore, the present results contradict the "release from refractoriness" explanation of the MMN elicitation.

10. Because of the constant 850 -msec interval between the onsets of consecutive test-masker stimulus pairs, 400 - and 300 -msec intertone intervals in forward masking can be interpreted as 370 - and $470-\mathrm{msec}$ intertone intervals of backward masking (test-and masking-tone durations of 25 and $55 \mathrm{msec}$ should also be taken into account).

(Manuscript received October 1, 1991; revision accepted for publication September 25, 1992.) 